\title{
Treinamento de consciência fonológica para pessoas com necessidade educacionais especiais no Brasil: uma revisão sistemática
}

Phonological awareness training for people with special educational needs in Brazil: a systematic review

Capacitación en conciencia fonológica para personas con necesidades educativas especiales en Brasil: una revisión sistemática

Layse Maria dos Santos Ferreira

Mestra pela Universidade Estadual de Ciências da Saúde de Alagoas, Maceió, AL, Brasil

E-mail: layse.msf2@gmail.com ORCID: https://orcid.org/0000-0002-8315-2047

Carmen Silvia Motta Bandini

Professora doutora da Universidade Estadual de Ciências da Saúde de Alagoas, Maceió, AL, Brasil

E-mail: csmbandini@gmail.com ORCID: https://orcid.org/0000-0002-4731-5785

Heloisa Helena Motta Bandini

Professora pós-doutora da Universidade Estadual de Ciências da Saúde de Alagoas, Maceió, AL, Brasil E-mail: heloisabandini@gmail.com ORCID: https://orcid.org/0000-0002-7320-2637

Recebido em 21 de abril de 2020

Aprovado em 24 de fevereiro de 2021

Publicado em 23 de março de 2021

\section{RESUMO}

O desempenho dos alunos brasileiros em leitura e escrita, tanto com desenvolvimento típico, quanto atípico, está muito abaixo do esperado e diferentes fatores vêm sendo levantados como causa para esse fracasso. Dos fatores em questão, dois vêm sendo debatidos: 1) alguns alunos necessitam de condições educacionais especiais não oferecidas nas escolas, por apresentarem transtornos do desenvolvimento, alterações neurológicas, deficiência auditiva ou síndromes que afetam a capacidade de aprendizagem e 2) a metodologia adotada pelas escolas não leva em consideração que as habilidades de consciência fonológica (CF), instrução fônica, vocabulário e memória operacional são essenciais para o processo de alfabetização. Esta revisão sistemática teve por objetivo mapear e analisar as pesquisas interventivas que visavam ensinar CF para pessoas com necessidades educacionais especiais, realizadas no Brasil. Como resultado, integraram essa revisão 27 estudos publicados de 2007 a 2018, sendo que 13 realizaram intervenções com indivíduos com dificuldade de aprendizagem, 4 com deficiência intelectual, 2 com dislexia, 2 com paralisia cerebral, 3 com Síndrome de Down, 1 com Síndrome de Down concomitante a síndrome de Willams, 1 com crianças surdas e 1 deficientes auditivas. Como pode ser visto, poucos foram os estudos encontrados se considerada a variedade de características das populações estudadas e a demanda de programas de pós-graduação nas áreas de educação, ensino e psicologia existentes no país.

Palavras-chave: Consciência Fonológica; Leitura; Condições Educacionais Especiais. 
http://dx.doi.org/10.5902/1984686X43678

\section{ABSTRACT}

The performance of Brazilian students in reading and writing, with both typical and atypical development, is far below expectations and different factors that have been raised as a cause for this failure. Of the factors in question, two have been debated: 1) some students need special educational conditions not offered in schools, because they have developmental disorders, neurological disorders, hearing loss or syndromes that affect the learning ability and 2) the methodology adopted by schools don't take into account that the skills of phonological awareness (CF), phonic instruction, vocabulary and working memory are essential for the literacy process. This systematic review aimed to map and analyze interventional research aimed at teaching CF to people with special educational needs, carried out in Brazil. As a result, this review included 27 studies published from 2007 to 2018, of which 13 carried out interventions with individuals with learning difficulties, 4 with intellectual disabilities, 2 with dyslexia, 2 with cerebral palsy, 3 with Down syndrome, 1 with Down syndrome Down with Willams syndrome, 1 with deaf children and 1 hearing impaired. As can be seen, few studies were found when considering the variety of characteristics of the studied populations and the demand for graduate programs in the areas of education, teaching and psychology in the country.

Keywords: Phonological Awareness; Reading; Special Educational Conditions.

\section{RESUMEN}

El desempeño de los estudiantes brasileños en lectura y escritura, con desarrollo típico y atípico, está muy por debajo de las expectativas y los diferentes factores que se han planteado como causa de este fracaso. De los factores en cuestión, dos han sido debatidos: 1) algunos estudiantes necesitan condiciones educativas especiales que no se ofrecen en las escuelas, ya que tienen trastornos del desarrollo, trastornos neurológicos, problemas de audición o síndromes que afectan la capacidad de aprendizaje y 2) la metodología adoptada por las escuelas no tiene en cuenta que la conciencia fonológica (CF), la instrucción fónica, el vocabulario y las habilidades de memoria de trabajo son esenciales para el proceso de alfabetización. Esta revisión sistemática tuvo como objetivo mapear y analizar la investigación intervencionista dirigida a enseñar CF a personas con necesidades educativas especiales, realizada en Brasil. Como resultado, esta revisión incluyó 27 estudios publicados de 2007 a 2018, de los cuales 13 llevaron a cabo intervenciones con personas con dificultades de aprendizaje, 4 con discapacidad intelectual, 2 con dislexia, 2 con parálisis cerebral, 3 con síndrome de Down, 1 con síndrome de Down Abajo con el síndrome de Willams, 1 con niños sordos y 1 con discapacidad auditiva. Como se puede ver, se encontraron pocos estudios al considerar la variedad de características de las poblaciones estudiadas y la demanda de programas de posgrado en las áreas de educación, enseñanza y psicología en el país.

Palabras clave: Consciência Fonológica; Lectura; Condiciones Educativas Especiales. 
http://dx.doi.org/10.5902/1984686X43678

\section{Introdução}

No Brasil, o índice de fracasso escolar é alarmante. Na última década, o país vem apresentando um desempenho muito abaixo do esperado em avaliações importantes de habilidades de leitura, aritmética e ciências. Dados do último relatório do programa internacional de avaliação de estudantes, disponibilizados pelo Instituto Nacional de Estudos e Pesquisas Educacionais Anísio Teixeira [INEP] (BRASIL, 2019), mostram que $50 \%$ dos adolescentes com idade de 15 anos ou mais não apresentavam o desempenho mínimo em leitura esperado para essa faixa etária, o que significa que estavam aptos somente a ler textos simples, não conseguindo compreender o propósito do texto e encontrar informações explícitas.

Apesar dos alunos brasileiros figurarem entre os estudantes com mais baixo desempenho em leitura em provas internacionais, as causas do fracasso escolar ainda são debatidas. Geralmente, o mau desempenho é justificado por características relativas a quem aprende, dando ênfase maior a fatores econômicos, psicossociais e cognitivos em detrimento à investigação de outras variáveis que podem estar envolvidas nesse aprendizado, como a pouca estimulação de habilidades consideradas essenciais (SEABRA; CAPOVILLA, 2010; ANTUNES; FREIRE; CRENITTI, 2013).

Algumas habilidades vêm sendo consideradas essenciais para o processo de alfabetização ser eficiente por uma parte importante da literatura atual: consciência fonológica (CF), instrução fônica, vocabulário, memória operacional e atenção (CAPOVILLA; GUTSCHOW; CAPOVILLA, 2004; CAPOVILLA; DIAS, 2008; BANDINI; BANDINI; RACIARO-NETO, 2017; PESTUN et al., 2010). Dentre essas habilidades, a instrução fônica ocupa lugar de destaque. Diversos estudos (SEABRA; CAPOVILLA, 2010; CAPOVILLA; DIAS; MONTIEL, 2007; PESTUN et al., 2010) apontam que as dificuldades apresentadas por crianças na aquisição de leitura e de escrita são de natureza fonológica e que o ensino explícito e sistemático desta habilidade pode favorecer a capacidade de leitura e de escrita em diferentes populações e séries. Sendo assim, métodos fônicos, que defendem a apropriação do código alfabético pela criança, acreditando que a alfabetização passa pelo desenvolvimento da CF e pela descoberta das correspondências grafemasfonemas, parecem ser bastante indicados para uma alfabetização adequada.

Apesar da relevância dos métodos que trabalham questões de natureza fonológica estar sendo amplamente comentada na literatura nacional e internacional, no Brasil, esses métodos não são conhecidos de forma aprofundada pelos professores, sendo bastante 
http://dx.doi.org/10.5902/1984686X43678

criticados e pouco utilizados nas escolas. Isso se deve pela influência das Políticas Curriculares Nacionais (PCNs), que são baseadas em uma perspectiva alinhada com o Método Global, referenciado nas ideias de educadores como Paulo Freire e Emília Ferreiro. Apesar da baixa inserção nas escolas, há já relatos na literatura de que, quando implementados no contexto escolar de alfabetização, os métodos fônicos apresentam bons resultados (ANDRADE, 2012).

Estudos mostram que o ensino de CF e o aprimoramento da memória devem acontecer de forma sistemática durante os anos escolares (GIDRI; KESKE-SOARES; MOTA, 2007; GRANZOTTI et al., 2013; CARDOSO; SILVA; PEREIRA, 2013). CF consiste na capacidade de discriminar e manipular os segmentos da fala, ou seja, adicionar, transpor, segmentar, substituir palavras, sílabas e fonemas. Essa habilidade se divide em habilidades suprafonêmicas (consciência silábica, rima e aliteração) e consciência fonêmica. É considerada pré-requisito para estabelecer a relação fonema-grafema e considerada altamente eficaz no ensino de habilidades de leitura e de escrita (SEABRA; CAPOVILLA, 2010; ANTUNES; FREIRE; CRENITTI, 2013).

Alunos que necessitam de condições educacionais especiais, por apresentarem transtornos do desenvolvimento, transtornos de aprendizagem ou alterações neurológicas ou sensoriais e síndromes genéticas, necessitam de uma programação de ensino ainda mais rigorosa. Inserem-se nesses casos, a deficiência intelectual (DI), a dislexia, a paralisia cerebral, a surdez, a deficiência auditiva, a Síndrome de Down, entre outros quadros que afetam de uma forma ou de outra, a capacidade do indivíduo de aprender.

Os transtornos do desenvolvimento têm início antes do período escolar, acarretando prejuízos na funcionalidade em diversas áreas como social, pessoal e acadêmica. Segundo - Manual Diagnostico e Estatísticos de Transtornos Mentais [DSM-5] (AMERICAN PSYCHIATRIC ASSOCIATION, 2014), a deficiência intelectual (DI), tem início antes dos 18 anos e os prejuízos funcionais são tanto intelectuais quanto adaptativos, nos domínios conceitual, social e prático. Inúmeros fatores podem causar DI, entre eles, síndromes como a Síndrome de Down, que consiste em uma alteração genética (BARBY; GUIMARÃES, 2016).

Os transtornos de aprendizagem manifestam-se, inicialmente, durante os anos de escolaridade formal, caracterizando-se por dificuldades persistentes e prejudiciais nas habilidades acadêmicas básicas de leitura, escrita e/ou aritmética. A dislexia, que consiste em um dos vários transtornos de aprendizagem, é um termo alternativo usado em 
http://dx.doi.org/10.5902/1984686X43678

referência a um padrão inesperado para a idade de habilidades acadêmicas e cognitivas, caracterizado por problemas no reconhecimento preciso ou fluente na leitura, dificuldade de decodificar palavras isoladas e em soletração e ortografia (AMERICAN PSYCHIATRIC ASSOCIATION, 2014; SEABRA; CAPOVILLA, 2010).

Entre as populações que se enquadram em necessidades educacionais especiais, está também a com paralisia cerebral, que abrange um grupo heterogêneo de síndromes clínicas, todas caracterizadas por déficit motor e/ou disfunção postural. Estas alterações surgem como consequência de uma lesão encefálica ocorrida previamente, sem caráter progressivo, gerada por uma variedade de causas e podem acometer aspectos cognitivos, de comunicação e sensoriais (BINHA; MARCIEL; BEZERRA, 2018). Outro quadro que necessita de educação especial é a deficiência auditiva, que segundo De Souza e Bandini (2007), dificulta ou impede a aquisição da linguagem, prejudicando o desenvolvimento do indivíduo.

O Instituto Brasileiro de Geografia e Estatística [IBGE] (2010) apresentou, em seu último Censo, que existem 45.606.048 pessoas vivendo com algum tipo de deficiência no Brasil, ou seja, $23,9 \%$ da população total do país. Esse levantamento leva em consideração deficiências intelectual, visual, motora, auditiva e mental. Ainda são escassos estudos que estimem a prevalência de transtornos do desenvolvimento e outras populações com necessidades educacionais especiais no país, assim como, os que dimensionem o desempenho e o ensino dessa população em habilidades acadêmicas.

Diante desse cenário e da escassez de recursos e métodos que figurem como alternativas para melhorar o desempenho dos alunos no país, estudos vêm sendo conduzidos de forma a gerar recursos educativos, ou metodologias efetivas visando reduzir as dificuldades do aluno e favorecer a aprendizagem de habilidades acadêmicas. Nesse contexto, o presente estudo caracteriza-se como revisão sistemática e tem por objetivo mapear, analisar e possibilitar uma fonte de informações sintetizada sobre as pesquisas interventivas que visam ensinar CF para pessoas com necessidades educacionais especiais, realizadas no Brasil.

\section{Método}

Nesse estudo de revisão sistemática foram mapeados os estudos publicados em português, realizados no Brasil, independentemente do tipo de intervenção, delineamento ou metodologia de análise de dados, que ensinavam as habilidades de consciência 
http://dx.doi.org/10.5902/1984686X43678

fonológica para crianças com necessidades educacionais especiais. Para uma visão geral do panorama das intervenções, não foi delimitado período de tempo ou utilizado qualquer tipo de filtro que pudesse de alguma forma, reduzir a amostra. Foram excluídos os estudos que possuíam apenas a avaliação da habilidade de CF, não descrevendo ou não possuindo procedimento de treino, textos indisponíveis online ou que apresentassem apenas resumos nas bases de dados e estudos de revisão de literatura.

As fontes de informação utilizadas foram às bases de dados: Scielo, Biblioteca Virtual em Saúde (BVS), LILACS, Biblioteca Digital de Teses e Dissertações (BVTD). O acesso às fontes ocorreu em março de 2020. A base de dados foi acessada, digitando-se as palavras-chaves e operadores booleanos no campo de busca. A busca foi realizada por dois pesquisadores independentes e estruturada em cada base de dados, seguindo 0 critério de palavras-chaves para diferentes necessidades educacionais especiais selecionadas pelas autoras. Cada pesquisador realizou dez buscas, cruzando descritores e seus sinônimos encontrados na base de Descritores em Ciências da Saúde (DECS) relacionados às habilidades que se pretendiam investigar (CF, leitura, educação, educar, programas de alfabetização, programas de treinamento, treinamento, oficinas de trabalho, workshops e educação especial), com diferentes condições de indivíduos que apresentam necessidades educacionais especiais, a saber: a) Síndrome de Down, trissomia 21, trissomia do cromossomo 21, mongolismo; b) transtornos de aprendizagem, deficiências do aprendizado, transtornos de aprendizado, transtorno do desenvolvimento acadêmico, deficiências da aprendizagem; c) síndrome; d) distúrbio; e) transtorno; f) doença de little, diplegia espástica, paralisia cerebral, diplégica infantil, paralisia cerebral monoplégica, paralisia cerebral quadriplégica infantil; g) dislexia, dificuldade de desenvolvimento da leitura, transtorno da leitura, transtorno do desenvolvimento da leitura, dislexia do desenvolvimento, alexia; h) surdez, surdas, deficiente auditivo, deficiência auditiva, perda da audição, perda da capacidade auditiva, hipoacusia, deficiência intelectual; i) retardo mental, deficiência mental, retardamento mental, idiotia. As palavras-chave visaram elaborar uma estratégia de busca abrangente, que possibilitasse a recuperação do maior número possível de estudos realizados em diferentes populações.

Todos os estudos apresentados pela base de dados pesquisada foram capturados e encaminhados para uma planilha em Excel, que estava nomeada por base de dados e subdividida em planilhas por tipos de necessidades educacionais especiais pesquisadas, ou seja, por grupo de palavras-chaves e operadores booleanos pesquisados. 
http://dx.doi.org/10.5902/1984686X43678

Foi realizada uma primeira busca utilizando os descritores acima relacionados e, após isso, foi feita a exclusão dos estudos duplicados. Os estudos derivados dessa primeira exclusão foram submetidos à análise crítica, seguindo os critérios de inclusão e exclusão estabelecidos. Iniciou-se a leitura dos títulos e resumos pelos dois revisores, que selecionaram apenas os estudos que seguiam os critérios de elegibilidade.

Os revisores chegaram a um percentual de concordância de $98,57 \%$ em relação aos estudos a serem incluídos na pesquisa, calculado através da formula: IC = concordância/concordância + discordância x 100. Esse índice mostra que houve a discordância em relação à inclusão de apenas um estudo. Esse foi lido na integra, revisados os critérios de inclusão e exclusão e discutidos entre os revisores, que decidiram em consenso pela inclusão do estudo na pesquisa.

A extração e síntese dos dados se deram através da leitura na íntegra dos estudos selecionados. Foram selecionadas informações sobre o autor, data de publicação, tipo do estudo, participantes, intervenção e conclusão, assim como, revista e Qualis dos estudos publicados, tipo de pós-graduação em que as dissertações e teses foram conduzidas.

\section{Resultados e discussão}

Na primeira busca foi rastreado um total de 240 estudos e, após a retirada dos títulos em duplicidade, 70 estudos permaneceram na amostra para serem submetidos à análise crítica, seguindo os critérios de inclusão e exclusão estabelecidos. Após toda a análise, chegou-se aos 27 estudos que integraram essa revisão.

Os estudos que integraram a revisão foram publicados entre os anos de 2007 e 2018. Dividem-se em 10 artigos, 10 monografias e 7 teses. Grande parte dos artigos foi publicada em revistas de Qualis A1 para Ensino (ver Tabela 1), sendo que 5 deles tem como área de conhecimento a Educação e/ou Educação Especial, 3 a Fonoaudiologia e/ou Comunicação e os demais, a Psicologia.

Os dados apresentados na Tabela 1 demonstram o interesse de educadores pelo desenvolvimento da competência de CF o que se justifica, já que a literatura (SEABRA; CAPOVILLA, 2010; CAPOVILLA; GUTSCHOW; CAPOVILLA, 2004; BANDINI; BANDINI; RACIANO-NETO, 2017) aponta a CF e a linguagem como pré-requisitos para estabelecer a relação fonema-grafema, habilidade importante na aquisição de leitura e escrita. No entanto, os relatórios de avaliação quadrimestral 2017 da Coordenação de Aperfeiçoamento de Pessoal de Nível Superior [CAPES] (BRASIL, 2017a; BRASIL, 
http://dx.doi.org/10.5902/1984686X43678

2017b; BRASIL, 2017c) apresentam que no país existem 170 programas de pósgraduação na área da educação, 140 para ensino e 84 em psicologia, ou seja, a quantidade de estudos nacionais sobre o tema é reduzida diante da quantidade de programas de pós-graduação.

Tabela 1 - Dados gerais de artigos selecionados

\begin{tabular}{|c|c|c|}
\hline Autor & Revista & $\begin{array}{c}\text { Ano/ } \\
\text { Qualis Ensino }\end{array}$ \\
\hline $\begin{array}{c}\text { ANTUNES, FREIRE e } \\
\text { CRENITTI }\end{array}$ & Distúrbios da Comunicação & 2013/B3 \\
\hline BARBY e GUIMARÃES & Revista Brasileira de Educação Especial & 2016/A1 \\
\hline COELHO e BASTOS & Psicologia da Educação & 2017/B1 \\
\hline FEKUDA e CAPELLINI & Psicologia: Reflexão e Critica & 2012/A1 \\
\hline FRIAS et al. & $\begin{array}{c}\text { Revista da Sociedade Brasileira de } \\
\text { Fonoaudiologia }\end{array}$ & 2008/- \\
\hline $\begin{array}{l}\text { HEIN, TEIXEIRA, SEABRA e } \\
\text { MARCEDO }\end{array}$ & Revista Brasileira de Educação Especial & 2010/A1 \\
\hline NOVAIS, MISHIMA, e SANTOS & Revista Psicopedagogia & 2013/B1 \\
\hline PAIXÃO, ASSIS e OLIVEIRA & $\begin{array}{l}\text { Revista Brasileira de Terapia } \\
\text { Comportamental e Cognitiva }\end{array}$ & 2014/A4 \\
\hline PELOSI et al. & Revista Brasileira de Educação Especial & 2018/A1 \\
\hline DE SOUZA e BANDINI & Paideia & 2007/A1 \\
\hline
\end{tabular}

Fonte: Elaborada pelas autoras a partir de dados da pesquisa (2020).

Dos estudos recrutados, 62,96\% são dissertações e teses (ver Tabela 2), o que sugere que estratégias de ensino que busquem desenvolver habilidades como CF estão sendo desenvolvidas em maioria nos programas de pós-graduação nas universidades do país. Todavia, esses trabalhos distribuem-se pelo Brasil de forma desigual, 15 estudos concentram-se na região sudeste, sendo 1 no Rio de Janeiro e 15 em São Paulo e os demais (2 estudos) foram realizados na região Norte (Pará). Esse fato demonstra que os estudos sobre o tema se concentram nos programas de pós-graduação do estado de São Paulo e, dessa forma, outras regiões apresentam carência em estudos na área. 
http://dx.doi.org/10.5902/1984686X43678

Tabela 2 - Estudos realizados em programas de pós-graduação do Brasil

\begin{tabular}{|c|c|c|}
\hline Autor & Mestrado/Universidade & Ano \\
\hline $\begin{array}{l}\text { ANDRADE, Elizabete } \\
\text { Maria de Almeida }\end{array}$ & $\begin{array}{l}\text { Distúrbio do desenvolvimento/Universidade Presbiteriana } \\
\text { Mackenzie }\end{array}$ & 2012 \\
\hline $\begin{array}{l}\text { ARAUJO, Márcia } \\
\text { Wilma Monteiro de }\end{array}$ & Teoria e pesquisa do comportamento/UFPA & 2007 \\
\hline $\begin{array}{l}\text { BRITO, Danielle } \\
\text { Abranches }\end{array}$ & $\begin{array}{l}\text { Educação: educação inclusiva e processos } \\
\text { educacionais/UERJ }\end{array}$ & 2014 \\
\hline MEI, Chi Kow & $\begin{array}{l}\text { Distúrbio do desenvolvimento/Universidade Presbiteriana } \\
\text { Mackenzie }\end{array}$ & 2007 \\
\hline $\begin{array}{l}\text { PAIXÃO, Glenda } \\
\text { Miranda da }\end{array}$ & Teoria e pesquisa do comportamento/UFPA & 2012 \\
\hline $\begin{array}{l}\text { RODRIGUES, Paulina } \\
\text { do Nascimento }\end{array}$ & Educação Especial/UFSCAR & 2017 \\
\hline SAS, Roberta Moreno & Educação Especial/UFSCAR & 2009 \\
\hline SILVA, Claudia da & Educação: Ensino na Educação Brasileira/UNESP & 2009 \\
\hline $\begin{array}{l}\text { SOUZA, Noemi Tamar } \\
\text { Américo de }\end{array}$ & Educação: Psicologia da Educação/PUC & 2018 \\
\hline Autor & Doutorado/Universidade & Ano \\
\hline $\begin{array}{l}\text { CARVALHO, Lina } \\
\text { Maria de Moraes }\end{array}$ & Educação, psicologia da educação/USP. & 2010 \\
\hline $\begin{array}{l}\text { DINIS, Neusa Lopes } \\
\text { Bispo }\end{array}$ & Psicologia escolar e desenvolvimento humano/USP & 2008 \\
\hline FREIRE, Thais. & $\begin{array}{c}\text { Ciências no programa de fonoaudiologia: Processos e } \\
\text { distúrbio de comunicação/USP Bauru }\end{array}$ & 2018 \\
\hline $\begin{array}{l}\text { LIMA, Solange de } \\
\text { Freitas Branco }\end{array}$ & $\begin{array}{l}\text { Distúrbio do desenvolvimento/Universidade Presbiteriana } \\
\text { Mackenzie }\end{array}$ & 2015 \\
\hline $\begin{array}{l}\text { MURPHY, Cristina } \\
\text { Ferraz Borges }\end{array}$ & Ciências: comunicação humana/USP & 2008 \\
\hline REIS, M. G. & Educação: Educação Especial/UNESP & 2018 \\
\hline SERGIN, Miriam & $\begin{array}{c}\text { Distúrbio do desenvolvimento/Universidade Presbiteriana } \\
\text { Mackenzie }\end{array}$ & 2015 \\
\hline
\end{tabular}

Fonte: Elaborada pelas autoras a partir de dados da pesquisa (2020). 
http://dx.doi.org/10.5902/1984686X43678

Grande parte dos estudos selecionados utiliza como participantes crianças com riscos para dificuldades de aprendizagem , totalizando 13 estudos. Os demais dividem-se em: a) 4 que realizaram intervenção com deficiência intelectual; b) 2 com dislexia; c) 2 com paralisia cerebral; d) 3 com Síndrome de Down; e) 1 com Síndrome de Down concomitante a Síndrome de Willams; f) 1 com crianças surdas e g) 1 deficientes auditivas. Esses dados corroboram a ideia de que o método fônico tem se mostrado eficaz para crianças de diversas populações, idades e séries, ou seja, vem se apresentado o mais adequado ao ensino de pessoas com e sem diagnósticos específicos matriculadas no ensino regular, assim como, para pessoas com ou sem risco para dificuldade de aprendizagem (SEABRA; CAPOVILLA, 2010).

Os dados demonstram que grande parte dos estudos tem como amostra os participantes inseridos no grupo de risco de dificuldade de aprendizagem ${ }^{1}$, os demais estudos subdividindo-se em outras áreas, o que parece sugerir o interesse pela relação entre CF e leitura em uma população que já apresenta fracasso escolar e não possui diagnósticos de causas orgânicas que justifiquem o baixo desempenho em habilidades acadêmicas. Com isso, os dados apresentados demonstram preferência dos pesquisadores brasileiros em estudos com um tipo de amostra, participantes com risco para dificuldade de aprendizagem, em detrimento de outras, com diagnóstico (Síndrome de Down, Paralisia Cerebral, Síndrome de Willamys, Surdas, Disléxicos, entre outras).

Os estudos em sua maioria possuem análise de dados quantitativa. Como pode ser visto na Tabela 3, 12 estudos são do tipo estudos clínicos de caso controle com delineamento pré e pós-teste, 13 são estudos clínicos de delineamento intrassujeitos, ou seja, os resultados dos participantes são comparados com eles mesmos antes e após a intervenção e um deles é um estudo qualitativo. A quantidade de estudos envolvendo intervenções educacional visando estimular CF em pessoas de diversas populações e a correlação dessa habilidade com 0 desempenho em leitura e escrita reafirma 0 posicionamento de uma parte da literatura (SEABRA; CAPOVILLA, 2010; CAPOVILLA; DIAS, 2008) quanto a evidências científica do ensino de CF. Além disso, o grande número de estudos de delineamento intrassujeito, ver Tabela 3 , demonstra o interesse dos pesquisadores em apresentar o efeito das intervenções comparando os dados de desempenho final com os de linha de base de cada participante, favorecendo uma análise qualitativa do desempenho aos dados quantitativos. 
Tabela 3 - Tipo de estudo e intervenção

(continua)

\begin{tabular}{|c|c|c|c|}
\hline Autor/Ano & Amostra & Tipo de Estudo & Intervenção \\
\hline $\begin{array}{l}\text { Andrade } \\
\text { (2012) }\end{array}$ & 19 escolares: DA & $\begin{array}{l}\text { Estudo clínico } \\
\text { Caso controle } \\
\text { Delineamento } \\
\text { pré e pós-teste. }\end{array}$ & $\begin{array}{l}\text { Treinamento dos professores e alunos; } \\
\text { Software alfabetização fônica } \\
\text { computadorizada (SEABRA et al., 2010); } \\
\text { Livro: Alfabetização: Método Fônico } \\
\text { (CAPOVILLA; CAPOVILLA, 2007). } \\
\text { Treino de CF Alfabetização Fônica: } \\
\text { Construindo competências de leitura e escrita } \\
\text { (SEABRA; CAPOVILLA, 2010) }\end{array}$ \\
\hline $\begin{array}{l}\text { Antunes, } \\
\text { Freire e } \\
\text { Crenitti } \\
(2013)\end{array}$ & 10 escolares: DA & $\begin{array}{l}\text { Estudo clínico } \\
\text { Delineamento } \\
\text { Intrasujeitos }\end{array}$ & $\begin{array}{l}\text { Aplicação do programa de remediação } \\
\text { fonológica proposto por Silva e Capellini (2011). }\end{array}$ \\
\hline $\begin{array}{l}\text { Araújo } \\
\text { (2007) }\end{array}$ & $\begin{array}{l}1 \text { criança e } 2 \\
\text { adolescentes: } \\
\text { Dislexia }\end{array}$ & $\begin{array}{l}\text { Estudo clínico } \\
\text { Delineamento } \\
\text { Intrasujeitos }\end{array}$ & $\begin{array}{l}\text { Treino de formação de classe de equivalência; } \\
\text { Treino de CF (consciência de palavras e } \\
\text { consciência silábica), elaborado pelo } \\
\text { pesquisadora. }\end{array}$ \\
\hline $\begin{array}{l}\text { Barby e } \\
\text { Guimarães } \\
(2016)\end{array}$ & 5 crianças: SW & $\begin{array}{l}\text { Estudo clínico } \\
\text { Delineamento } \\
\text { intrasujeitos }\end{array}$ & $\begin{array}{l}\text { Treino de CF, com atividades adaptadas de: } \\
\text { Capovilla (1999), Bandini (2003), Sás (2009), } \\
\text { Carvalho (2010), Burgoyne et al. (2012); } \\
\text { Apoio de material concreto e jogos } \\
\text { pedagógicos. }\end{array}$ \\
\hline $\begin{array}{l}\text { Brito } \\
(2014)\end{array}$ & 4 jovens: DI & $\begin{array}{l}\text { Estudo clínico } \\
\text { Delineamento } \\
\text { intrasujeitos }\end{array}$ & $\begin{array}{l}\text { Treino de CF, com recursos instrucionais } \\
\text { retirados de: Almeida e Duarte (2003), } \\
\text { Capovilla e Capovilla (2000) e Capovilla et al. } \\
(2005) \text {. }\end{array}$ \\
\hline $\begin{array}{l}\text { Carvalho } \\
\text { (2010) }\end{array}$ & 18 crianças: DA & $\begin{array}{l}\text { Estudo clínico } \\
\text { Caso controle } \\
\text { Delineamento } \\
\text { pré e pós-teste. }\end{array}$ & $\begin{array}{l}\text { Habilidades metalinguísticas de CF elaborado } \\
\text { pela pesquisadora. }\end{array}$ \\
\hline $\begin{array}{l}\text { Coelho e } \\
\text { Bastos } \\
(2017)\end{array}$ & 1 menina: DI & $\begin{array}{l}\text { Estudo clínico } \\
\text { Caso controle } \\
\text { Delineamento } \\
\text { pré e pos teste. }\end{array}$ & $\begin{array}{l}\text { Programa de treinamento de CF utilizando o } \\
\text { software Alfabetização } \quad \text { Fônica } \\
\text { Computadorizada (SEABRA et al., 2010) }\end{array}$ \\
\hline $\begin{array}{l}\text { Dinis } \\
(2008)\end{array}$ & 22 escolares: DA & $\begin{array}{l}\text { Estudo clínico } \\
\text { Caso controle } \\
\text { Delineamento } \\
\text { pré e pos teste. }\end{array}$ & $\begin{array}{l}\text { Programa de treinamento de CF elaborado pela } \\
\text { pesquisadora. }\end{array}$ \\
\hline $\begin{array}{l}\text { Fekuda e } \\
\text { Capellini } \\
(2012)\end{array}$ & 60 escolares: DA & $\begin{array}{l}\text { Estudo clínico } \\
\text { Caso controle } \\
\text { Delineamento } \\
\text { pré e pos teste. }\end{array}$ & $\begin{array}{l}\text { Programa de treinamento das habilidades } \\
\text { fonológicas } \\
\text { grafemafonema, tomando como base o estudo } \\
\text { de Schneider et al., } 2000 \text {. }\end{array}$ \\
\hline
\end{tabular}


Tabela 3 - Tipo de estudo e intervenção

(continua)

\begin{tabular}{|c|c|c|c|}
\hline Autor/Ano & Amostra & Tipo de Estudo & Intervenção \\
\hline $\begin{array}{l}\text { Freire } \\
(2018)\end{array}$ & $\begin{array}{l}69 \text { escolares: } \\
\text { DA }\end{array}$ & $\begin{array}{l}\text { Estudo clínico } \\
\text { Caso controle } \\
\text { Não } \\
\text { randomizado } \\
\text { Duplo cego. }\end{array}$ & $\begin{array}{l}\text { Programa de treinamento adaptada da } \\
\text { proposta de Kruse et al.(2015); } \\
\text { Formação do professor. }\end{array}$ \\
\hline $\begin{array}{l}\text { Frias et al. } \\
(2008)\end{array}$ & $\begin{array}{l}1 \text { criança: } \\
\text { Soropositiva e } \\
\text { DA }\end{array}$ & $\begin{array}{l}\text { Estudo clínico } \\
\text { Delineamento } \\
\text { intrasujeitos }\end{array}$ & $\begin{array}{l}\text { Programa terapêutico fonológico fechado } \\
\text { desenvolvido pela pesquisadora } \\
\text { (Processamento Auditivo, CF, Leitura e } \\
\text { Escrita). }\end{array}$ \\
\hline $\begin{array}{l}\text { Hein et al. } \\
(2010)\end{array}$ & 22 crianças: DI & $\begin{array}{l}\text { Estudo clínico } \\
\text { Caso controle } \\
\text { Delineamento } \\
\text { pré e pos teste. }\end{array}$ & $\begin{array}{l}\text { Programa de treinamento de CF utilizando o } \\
\text { software Alfabetização } \quad \text { Fônica } \\
\text { Computadorizada (SEABRA et al., 2010) }\end{array}$ \\
\hline $\begin{array}{l}\text { Lima } \\
(2015)\end{array}$ & $\begin{array}{l}4 \\
\text { crianças/família } \\
\text { /Professores: } \\
\text { SW }\end{array}$ & $\begin{array}{l}\text { Estudo clínico } \\
\text { Delineamento } \\
\text { intrasujeitos }\end{array}$ & $\begin{array}{l}\text { Treinamento de manejo comportamental em } \\
\text { sala de aula para professores; } \\
\text { Treinamento parental para manejo de } \\
\text { dificuldades emocionais e comportamentais do } \\
\text { filho dom SW; } \\
\text { Orientações do programa de treinamento para } \\
\text { cuidadores e professores; } \\
\text { Treino de CF utilizando o software } \\
\text { Alfabetização fônica computadorizada (Seabra } \\
\text { et al., 2010). }\end{array}$ \\
\hline $\begin{array}{l}\text { Mei } \\
(2007)\end{array}$ & $\begin{array}{l}23 \text { escolares: } \\
\text { DA }\end{array}$ & $\begin{array}{l}\text { Estudo clínico } \\
\text { Caso controle } \\
\text { Delineamento } \\
\text { pré e pós teste. }\end{array}$ & $\begin{array}{l}\text { Treino de CF utilizando o software } \\
\text { Alfabetização Fônica Computadorizada } \\
\text { (Seabra et al., 2010). }\end{array}$ \\
\hline $\begin{array}{l}\text { Murphy } \\
(2008)\end{array}$ & $\begin{array}{l}40 \text { crianças: } \\
\text { Dislexia }\end{array}$ & $\begin{array}{l}\text { Estudo clínico } \\
\text { Caso controle } \\
\text { Delineamento } \\
\text { pré e pós-teste. }\end{array}$ & $\begin{array}{l}\text { Desenvolvimento e aplicação de um software } \\
\text { de Treino de CF. }\end{array}$ \\
\hline $\begin{array}{l}\text { Novais, } \\
\text { Mishima e } \\
\text { Santos } \\
(2013)\end{array}$ & 47 crianças: DA & $\begin{array}{l}\text { Estudo clínico } \\
\text { Caso controle } \\
\text { Delineamento } \\
\text { pré e pós-teste. }\end{array}$ & $\begin{array}{l}\text { Programa de treinamento de CF adaptado de } \\
\text { Capovilla e Capovilla, } 2004 .\end{array}$ \\
\hline $\begin{array}{l}\text { Paixão } \\
\text { (2012) }\end{array}$ & 3 crianças: PC & $\begin{array}{l}\text { Estudo clínico } \\
\text { Delineamento } \\
\text { intrasujeitos }\end{array}$ & $\begin{array}{l}\text { Programa de treinamento utilizando o software } \\
\text { PROLER versão } 6.4 \text { (ASSIS; SANTOS, 2010). }\end{array}$ \\
\hline $\begin{array}{l}\text { Paixão, Assis } \\
\text { e Oliveira } \\
\text { (2014) }\end{array}$ & 3 crianças: PC & $\begin{array}{l}\text { Estudo clínico } \\
\text { Delineamento } \\
\text { intrasujeitos }\end{array}$ & $\begin{array}{l}\text { Programa de treinamento utilizando o software } \\
\text { PROLER versão } 6.4 \text { (ASSIS; SANTOS, 2010). }\end{array}$ \\
\hline
\end{tabular}


Tabela 3 - Tipo de estudo e intervenção

(conclusão)

\begin{tabular}{|c|c|c|c|}
\hline Autor/Ano & Amostra & Tipo de Estudo & Intervenção \\
\hline $\begin{array}{l}\text { Pelosi et al. } \\
(2018)\end{array}$ & 5 crianças: SD & $\begin{array}{l}\text { Estudo clínico } \\
\text { Delineamento } \\
\text { intrasujeitos }\end{array}$ & $\begin{array}{l}\text { Oficinas de atividades lúdicas, que incluíam o } \\
\text { treino de CF elaborado pelas pesquisadoras, } \\
\text { atividades livres e atividades gráficas para } \\
\text { serem realizadas em casa. }\end{array}$ \\
\hline $\begin{array}{l}\text { Reis } \\
(2018)\end{array}$ & 1 criança: DI & $\begin{array}{l}\text { Estudo clínico } \\
\text { Delineamento } \\
\text { intrasujeitos }\end{array}$ & $\begin{array}{l}\text { Programa de treinamento de CF elaborado pela } \\
\text { pesquisadora }\end{array}$ \\
\hline $\begin{array}{l}\text { Rodrigues } \\
\text { (2017) }\end{array}$ & 7 crianças: DA & $\begin{array}{l}\text { Estudo clínico } \\
\text { Caso controle } \\
\text { Delineamento } \\
\text { pré e pós-teste. }\end{array}$ & $\begin{array}{l}\text { Aplicação do programa Aprendendo a ler e a } \\
\text { escrever em pequenos passos [ALEPP] (DE } \\
\text { SOUZA; DE ROSE, } 2006 \text { ); } \\
\text { Programa de CF Alfabetização Fônica } \\
\text { Computadorizada (SEABRA et al., 2010). }\end{array}$ \\
\hline $\begin{array}{l}\text { Sas } \\
(2009)\end{array}$ & 8 crianças: SD & $\begin{array}{l}\text { Estudo clínico } \\
\text { Delineamento } \\
\text { intrasujeitos }\end{array}$ & $\begin{array}{l}\text { Programa de remediação fonológica } \\
\text { desenvolvido por Gonzélez, Espinel e } \\
\text { Rosquete (2002), adaptado para a população } \\
\text { brasileira por Salgado (2005). }\end{array}$ \\
\hline $\begin{array}{l}\text { Sergin } \\
(2015)\end{array}$ & $\begin{array}{l}3 \text { crianças: SD } \\
3 \text { Crianças: SW }\end{array}$ & $\begin{array}{l}\text { Estudo clínico } \\
\text { Delineamento } \\
\text { intrasujeitos }\end{array}$ & $\begin{array}{l}\text { Programa de treino de CF utilizando o software } \\
\text { Alfabetização Fônica Computadorizada } \\
\text { (SEABRA et al., 2010); } \\
\text { Atividades auxiliares desenvolvidas pela } \\
\text { pesquisadora. }\end{array}$ \\
\hline $\begin{array}{l}\text { Silva } \\
\text { (2009) }\end{array}$ & 40 escolares: DA & $\begin{array}{l}\text { Estudo clínico } \\
\text { Caso controle } \\
\text { Delineamento } \\
\text { pré e pós-teste. }\end{array}$ & $\begin{array}{l}\text { Adaptação do programa de remediação } \\
\text { fonológica e leitura descrita por Thatcher, } \\
\text { Hulme e Ellis (1994). }\end{array}$ \\
\hline $\begin{array}{l}\text { De Souza e } \\
\text { Bandini } \\
(2007)\end{array}$ & $\begin{array}{l}4 \text { crianças: } \\
\text { Surdas }\end{array}$ & $\begin{array}{l}\text { Estudo clínico } \\
\text { Delineamento } \\
\text { intrasujeitos }\end{array}$ & $\begin{array}{l}\text { Programa de treino de CF para } \\
\text { crianças surdas usuárias de LIBRAS, } \\
\text { atividades foram adaptadas dos programas de } \\
\text { Capovilla (1998) e Bandini (2003) }\end{array}$ \\
\hline $\begin{array}{l}\text { Souza } \\
(2018)\end{array}$ & 7 escolares: DA & $\begin{array}{l}\text { Estudo clínico } \\
\text { Delineamento } \\
\text { intrasujeitos }\end{array}$ & $\begin{array}{l}\text { Programa de intervenção adaptado dos livros } \\
\text { Aprendendo a ler com as letras e sons, de } \\
\text { Puliezi (2016) e CF em crianças pequenas, de } \\
\text { Adams et al. (2006). }\end{array}$ \\
\hline $\begin{array}{l}\text { Yoshida } \\
\text { (2017) }\end{array}$ & 6 escolares: DA & Qualitativo & $\begin{array}{l}\text { Desenvolvimento e aplicação das instruções de } \\
\text { uso do livreto de estímulo de CF para alunos } \\
\text { com deficiência auditiva, aplicado aos } \\
\text { professores. }\end{array}$ \\
\hline
\end{tabular}

Fonte: Elaborada pelas autoras a partir de dados da pesquisa (2020).

Legenda: Dificuldade de Aprendizagem (DA), Síndrome de Down (SD), Deficiência Intelectual (DI), Sindrome de Willamys (SW), Paralisia Cerebral (PC). 
http://dx.doi.org/10.5902/1984686X43678

Quanto aos recursos educativos utilizados, a Tabela 3 mostra que 17 dos estudos selecionados utilizaram atividades e materiais lúdicos para realizar a intervenção com seus participantes, destes, 10 adaptaram atividades de programas de ensino criados e testados por outros pesquisadores e 7 criaram suas atividades.

Dos estudos analisados, 11 associaram o ensino de outra habilidade e/ou o uso de outras estratégias educacionais ao treino de CF. A exemplo, o estudo de Fekuda e Capellini (2012) que estudou a efetividade de um programa de treinamento, aplicado em crianças com dificuldade de aprendizagem e ensinou as habilidades fonológicas (rima, aliteração, consciência silábica), associando, durante todo o treino, o ensino da correspondência grafema-fonema que consiste na habilidade de converter o grafema na pronuncia fonêmica e vice versa. Já Araujo (2007) buscou treinar a formação de classe de equivalência, ou seja, ensinou explicitamente discriminações condicionais, a exemplo da relação palavra falada/figura; palavra falada/palavra impressa, a crianças com dislexia, testando a emergência de relações novas, entre estímulos da mesma classe de resposta, que ainda não foram ensinadas diretamente, como a relação figura/palavra impressa, intercalando com o treino de CF (consciência de palavras e consciência silábica).

Ainda em relação à Tabela 3, além da utilização dos materiais lúdicos, 9 estudos optaram por utilizar um software para favorecer o treino de CF, ou seja, fazem uso de recursos digitais associados a procedimentos de ensino com o objetivo de favorecer habilidades como CF, leitura, escrita, entre outros, e apresentam bons resultados. Essa medida corrobora a literatura da área que aponta o uso de tecnologias como ferramenta vantajosa para o ensino de diversas habilidades (KENSKI, 2012).

A Tabela 3 também mostra que o treino de responsáveis pelo cuidado (professores e pais) para aplicação e avaliação do programa de ensino que favorecessem o aprendizado de CF apresentou-se em 4 estudos. Esses dados mostram um baixo número desses treinamentos, mesmo diante das evidências que revelam a importância deles para a educação e para o aperfeiçoamento em aplicação de procedimentos com evidência científica visando favorecer pré-requisitos importantes para leitura e escrita (ANDRADE, 2012). Diversos autores, tais como Silva (2011), por exemplo, pontuam a importância do papel do professor em detrimento do uso da tecnologia, já que, até para a inserção efetiva das tecnologias em ambiente de aprendizagem é necessário à formação e conhecimento pedagógico. Ressaltam ainda, a importância de investimentos em programas de formação continuada para professores no contexto escolar, favorecendo a correlação prática-teoria, 
http://dx.doi.org/10.5902/1984686X43678

estimulando a compreensão das necessidades do contexto escolar em que esse está inserido, possibilitando acesso e/ou desenvolvimento de práticas com evidências científicas de forma a prever, diagnosticar e corrigir dificuldades do aluno em relação à aprendizagem da leitura e da escrita.

Diante do que foi exposto, é possível observar que em grande parte dos estudos, os pesquisadores realizaram as intervenções diretamente com as crianças. Em uma análise mais detalhada dos estudos categorizados na Tabela 4, é possível verificar que em 1 deles a intervenção foi realizada de forma direta com professores e alunos, em 2 a intervenção foi direta com professores e indireta com alunos e em outro a intervenção foi direta com professores visando treiná-los e posteriormente verificar sua perspectiva quanto ao trabalho, um estudo qualitativo.

Tabela 4 - Categorização dos tipos de intervenção

(continua)

\begin{tabular}{|c|c|c|c|}
\hline Categoria & Descrição & № artigos & Autores \\
\hline $\begin{array}{l}\text { Intervenção } \\
\text { com alunos }\end{array}$ & $\begin{array}{l}\begin{array}{l}\text { Selecionados estudos que abordem } \\
\text { intervenção }\end{array} \\
\text { com o objetivo de verificar se o ensino CF } \\
\text { em crianças com necessidades } \\
\text { educacionais especiais é eficaz. }\end{array}$ & 23 & $\begin{array}{l}\text { Antunes, Freire e Crenitti (2013) } \\
\text { Araujo (2017) } \\
\text { Barby e Guimarães (2016) } \\
\text { Brito (2014) } \\
\text { Carvalho (2010) } \\
\text { Coelho e Bastos(2017) } \\
\text { Dinis(2008) } \\
\text { Fekuda e Capellini (2012) } \\
\text { Frias et al. (2008) } \\
\text { Hein et al. (2010) } \\
\text { Lima (2015) } \\
\text { Mei (2007) } \\
\text { Murphy (2008) } \\
\text { Novais, Mishima e Santos } \\
\text { (2013) } \\
\text { Paixão (2012) } \\
\text { Paixão, Assis e Oliveira (2014) } \\
\text { Pelosi at al. (2018) } \\
\text { Reis (2018) } \\
\text { Rodrigues (2017) } \\
\text { Sas (2019) } \\
\text { Sergin (2015) } \\
\text { Silva (2009) } \\
\text { De Souza e Bandini (2007) } \\
\text { Souza (2018) }\end{array}$ \\
\hline
\end{tabular}


http://dx.doi.org/10.5902/1984686X43678

Tabela 4 - Categorização dos tipos de intervenção

(conclusão)

\begin{tabular}{|c|c|c|c|}
\hline Categoria & Descrição & № artigos & Autores \\
\hline $\begin{array}{l}\text { Intervenção } \\
\text { direta com } \\
\text { professores } \\
\text { e alunos }\end{array}$ & $\begin{array}{l}\text { Selecionados estudos que abordem: } \\
\text { - Intervenção direta com os professores } \\
\text { e/ou pais, com o objetivo de capacitar } \\
\text { cuidadores de crianças que apresentam } \\
\text { necessidades educacionais especiais. } \\
\text { - Intervenção direta a criança objetivando o } \\
\text { ensino CF em crianças que apresentam } \\
\text { necessidades educacionais especiais. }\end{array}$ & 1 & Lima (2005) \\
\hline $\begin{array}{l}\text { Intervenção } \\
\text { direta com } \\
\text { professores/ } \\
\text { indireta com } \\
\text { alunos }\end{array}$ & $\begin{array}{l}\text { Selecionados estudos que abordem } \\
\text { intervenção direta com os professores, } \\
\text { com o objetivo de promover a formação } \\
\text { para o ensino CF em crianças com } \\
\text { necessidades educacionais especiais. }\end{array}$ & 2 & $\begin{array}{l}\text { Andrade (2012) } \\
\text { Freire (2018) }\end{array}$ \\
\hline $\begin{array}{l}\text { Intervenção } \\
\text { direta com } \\
\text { professores/ } \\
\text { perspectiva } \\
\text { do } \\
\text { profissional }\end{array}$ & $\begin{array}{l}\text { Selecionados estudos que abordem } \\
\text { intervenção direta com os professores, } \\
\text { virando promover a formação para o } \\
\text { ensino CF em crianças com necessidades } \\
\text { educacionais especiais, verificando como } \\
\text { essa intervenção foi percebida pelos } \\
\text { profissionais envolvidos na pesquisa. }\end{array}$ & 1 & Yoshida (2017) \\
\hline
\end{tabular}

Fonte: Elaborada pelas autoras com base em Oliveira, Munter e Gonçalves (2019).

\section{Considerações Finais}

Este trabalho buscou mapear, analisar e sintetizar estudos que descrevessem práticas interventivas realizadas no Brasil com o objetivo de ensinar CF a pessoas com necessidades educacionais especiais. Embora a população seja diversificada, foi possível rastrear um número pequeno de estudos em relação à variedade de características da população estudada e ao grande número de programas de pós-graduação nas áreas de Educação, Ensino e Psicologia existentes no país. A despeito de quatro estudos terem como objetivo apresentar e treinar pais e professores para a utilização do ensino de CF e outras habilidades em sua prática diária, ainda são escassos estudos de casos ou estudos que favoreçam o conhecimento e acesso de profissionais a estratégias eficazes de ensino de habilidade de CF.

Todos os trabalhos aqui apontados demonstram resultados satisfatórios quanto ao ensino da habilidade de CF a pessoas com necessidades educacionais especiais, além de ressaltarem ganhos em habilidades como leitura, escrita associados ao treino dessa habilidade, corroborando o que aponta a literatura (SEABRA; CAPOVILLA, 2010; 
CAPOVILLA; DIAS; MONTIEL, 2007, PESTUN et al., 2010). A utilização de software é um recurso bastante utilizado para o ensino de habilidades acadêmicas, 9 dos 27 estudos utilizaram esse recurso para intervenção, apresentando bons resultados, assim como afirma Kenski (2012), que ressalta a utilização de recursos tecnológicos e de comunicação para favorecer o aprendizado. A utilização de atividades e materiais lúdicos não digitalizados ou informatizados ainda é um recurso adotado pelos pesquisadores, 18 estudos. O que se justifica pelo fácil acesso, baixo custo e evidências da eficácia no aprendizado.

A partir da análise de dados dessa revisão é possível verificar que estudos realizados no Brasil, mostram-se eficazes quando tem a finalidade de desenvolver habilidades de importância central para a aquisição da leitura e da escrita, como CF, quando associados a procedimentos de ensino amplamente testados e que visam contribuir para minimizar os problemas ocorridos na educação básica e favorecer o aprendizado de diversas populações e séries como, por exemplo, o treino de formação de classes de equivalência de estímulos (DE SOUZA et al., 2004).

\section{Referências}

AMERICAN PSYCHIATRIC ASSOCIATION. Manual diagnóstico e estatístico de transtornos mentais: DSM-5. 5를. Porto Alegre: Artmed, 2014.

ANDRADE, Elizabete Maria de Almeida. Abordagem Fônica para Remediar a Defasagem na aquisição de Leitura e Escrita: O papel da Capacitação de Professores. 2012. Dissertação (Mestrado em Distúrbios do Desenvolvimento)Universidade Presbiteriana Mackenzie, São Paulo, 2012. Disponível em: http://bdtd.ibict.br/vufind/Record/UPM_a2ad15ebb42fbbbb37a0d59936abdfcc. Acesso em: 18 abr. 2020.

ANTUNES, Lívia Gonçalves; FREIRE, Thais; CRENITTI, Patrícia Abreu Pinheiro. Programa de Remediação Fonológica em Escolares com Sinais de Risco para Dificuldade de Aprendizagem. Revista Distúrbios Comuns, São Paulo, 2, p. 225-236, ago. 2013. Disponível em: https://repositorio.usp.br/item/002743084. Acesso em: 18 abr. 2020.

\section{ARAUJO, Márcia Wilma Monteiro de. Habilidades Metafonológicas e}

\section{Desenvolvimento de Leitura e Escrita Recombinativas em Crianças com}

Diagnostico de Dislexia. 2007. Dissertação (Mestrado em Teoria e Pesquisa do Comportamento) - Centro de Filosofia e Ciências Humanas, Universidade Federal do Pará, Pará, 2007. Disponível em: http://www.repositorio.ufpa.br/jspui/handle/2011/1919. Acesso em: 18 abr. 2020. 
BANDINI, Heloisa Helena; BANDINI, Carmen Silvia; RACIANO-NETO, Ademar. Relations Between Reading, Vocabulary and Phonological Awareness in low-Income Children. Paideia, São Paulo, 68, p. 314-323, 2017.

BARBY, Ana Aparecida de Oliveira Machado; GUIMARÃES, Sandra Regina Kirchiner. Desenvolvimento de Habilidades Metafonológicas e Aprendizagem da Leitura e da Escrita em Alunos com Síndrome de Down. Revista Brasileira de Educação Especial, Marília, 3, p. 381-398, 2016. Disponível em: http://www.scielo.br/scielo.php?pid=S141365382016000300381\&script=sci_abstract\&tlng=pt. Acesso em 19 abr. 2020.

BINHA, Any Michelly Paquier; MARCIEL, Simone Carazzato; BEZERRA, Carla Cristine Andrade. Perfil epidemiológico dos pacientes com paralisia cerebral atendidos na AACD-São Paulo. Revista Acta de Fisiatria, São Paulo, 1 , p. 1-6, 2018.

BRASIL, Ministério da Educação. Relatório Brasil no PISA 2018. Brasília, DF, 2019. $158 p$.

BRASIL, Ministério da Educação. Relatório da Avaliação Quadrienal 2017: Psicologia. Brasília, DF, 2017a.108p. Disponível em:

https://capes.gov.br/images/documentos/Relatorios_quadrienal_2017/20122017-

Psicologia_relatorio-de-avaliacao-2017_final.pdf. Acesso em: $1 \overline{8}$ abr. 2020.

BRASIL, Ministério da Educação. Relatório da Avaliação Quadrienal 2017: Ensino. Brasília, DF, 2017b. 102p. Disponível em:

https://capes.gov.br/images/stories/download/avaliacao/relatorios-finais-quadrienal2017/20122017-ENSINO-quadrienal.pdf. Acesso em: 18 abr. 2020.

BRASIL, Ministério da Educação. Relatório da Avaliação Quadrienal 2017: Educação. Brasília, DF, 2017c. 93p. Disponível em:

http://capes.gov.br/images/documentos/Relatorios_quadrienal_2017/20122017-

Educacao_relatorio-de-avaliacao-quadrienal-2017_final.pdf. Acesso em: 18 abr. 2020.

BRITO, Danielle Abranches. Estimulando a Consciência Fonológica em Jovens com Deficiência Intelectual. 2014. Dissertação (Mestrado em educação)-Centro de Educação e Humanidades, Universidade do Estado do Rio de janeiro, Rio de Janeiro, 2014. Disponível em: http://www.bdtd.uerj.br/tde_busca/arquivo.php?codArquivo=7951. Acesso em: 18 abr. 2020

CAPOVILLA, Alessandra Gotuzo Seabra; DIAS, Natália Martins. Habilidades de linguagem oral e sua contribuição para a posterior aquisição de leitura. PSIC-Revista de Psicologia da Vetor Editora, São Paulo, 2, p.135-144, 2008. Disponível em: http://pepsic.bvsalud.org/pdf/psic/v9n2/v9n2a02.pdf. Acesso em: 18 abr. 2020.

CAPOVILLA, Alessandra Gotuzo Seabra; DIAS, Natália Martins; MONTIEL, José Maria. Desenvolvimento dos componentes da consciência fonológica no ensino fundamental e correlação com nota escolar. Psico-USF, São Paulo, 1 , p. 55-64, 2007.

CAPOVILLA, Alessandra Gotuzo Seabra; GUTSCHOW, Cláudia Regina Danelon; CAPOVILLA, Fernando César. Habilidades cognitivas que predizem competência de leitura e escrita. Psicologia: Teoria e Prática, São Paulo, 2, p.13-26, 2004. 
CARDOSO, Andreia Martins de Souza; SILVA, Mônica Marins da; PEREIRA, Mônica Medeiros de Brito. Consciência Fonológica e a Memória de Trabalho de Crianças com e sem Dificuldades na Alfabetização. CoDAS, São Paulo, 2 , p. 110-114, 2013. Disponivel em: http://www.scielo.br/scielo.php?pid=S2317-

17822013000200004\&script=sci_abstract\&tIng=pt. Acesso em: 18 abr. 2020.

CARVALHO, Fabrícia Bignotto de; CRENITTI, Patrícia Abreu Pinheiro; CIASCA, Sylvia Maria. Distúrbios de aprendizagem na visão do professor. Revista de Psicopedagogia, São Paulo, 75, p. 229-239, 2007.

CARVALHO, Lina Maria De Moraes. Consciência Fonológica e Sucesso na

Aprendizagem da Leitura e da Escrita: Melhor Prevenir do que Remediar. 2010. Tese (Doutorado em Educação). Pontifícia Universidade Católica de São Paulo, São Paulo, 2010. Disponível em: https://tede2.pucsp.br/handle/handle/15966. Acesso em: 18 abr. 2020.

COELHO, Cristina Lúcia Maia; BASTOS, Claudio Líra. A avaliação interativa e o software alfabetização fônica: um estudo de caso. Revista da Educação, São Paulo, 44, p. 57-66, 2017. Disponível em:

http://pepsic.bvsalud.org/scielo.php?script=sci_arttext\&pid=S1414-69752017000100006. Acesso em: 18 abr. 2020.

DE SOUZA, Deisy das Graças et al. Análise comportamental da aprendizagem de leitura e a construção de um currículo suplementar. In: Hubner, Maria Martha Costa. Análise do comportamento para a educação: Contribuições recentes. $1^{\circ}$ ed. Santo André: ESETec editores associados, 2004. P. 177-204.

DE SOUZA, Érika Costa; BANDINI, Heloisa Helena Motta. Programa de treinamento de consciência fonológica para crianças surdas bilíngues. Paidéia, São Paulo, 36, p. 123135, 2007. Disponível em: http://www.scielo.br/pdf/paideia/v17n36/v17n36a12.pdf. Acesso em: 18 abr. 2020.

DINIS, Neusa Lopes Bispo. Metalinguagem e Alfabetização: efeitos de uma intervenção para recuperação de alunos com dificuldades na aprendizagem da língua escrita. 2008. Tese (Doutorado em Psicologia)-Instituto de Psicologia, Universidade de São Paulo, São Paulo, 2008. Disponível em:

https://www.teses.usp.br/teses/disponiveis/47/47131/tde-09012009-144508/pt-br.php. Acesso em: 18 abr. 2020.

FEKUDA, Maryse Tomoko Matsuzawa; CAPELLIN, Simone Aparecida. Programa de Intervenção Fonológica Associado à Correspondência Grafema-fonema em Escolares de Risco para a Dislexia. Psicologia: Reflexão e Crítica, Porto Alegre, 4 , p. 783-790, 2012.

FREIRE, Thais. Ações da fonoaudiologia na escola: Programa da Estimulação da Consciência fonológica em Escolares do $1^{\circ}$ ano do Ensino Fundamental. 2018. Tese (Doutorado em Ciências)-Universidade de São Paulo, São Paulo, 2018. Disponível em: https://teses.usp.br/teses/disponiveis/25/25143/tde-01102018-211605/pt-br.php. Acesso em: 18 abr. 2020. 
FRIAS, Vivian Alvina de Camargo. et al. Distúrbios de leitura e escrita em portadora do vírus da imunodeficiência humana: estudo de caso. Revista da Sociedade Brasileira de Fonoaudiologia. São Paulo, 2 , p.179-185, 2008. Disponível em: https://repositorio.usp.br/bitstream/handle/BDPI/9183/art_FRIAS_Disturbios_de_leitura_e_e scrita_em_portadora_2008.pdf;jsessionid=730D3E31AA 4 F6C41944FCB76749314EF?sequ ence=1. Acesso em: 18 abr. 2020.

GIDRI, Gigiane; KESKE-SOARES, Márcia; MOTA, Helena Bolli. Memória de Trabalho, Consciência Fonológica e Hipótese de Escrita. Pró-Fono, São Paulo, 3, p. 313-322, 2007. Disponível: http://www.scielo.br/pdf/pfono/v19n3/a10v19n3.pdf. Acesso em: 18 abr. 2020.

GRANZOTTI, Raphaela Barroso Guedes. et al. Memória de Trabalho Fonológica em Crianças com Dificuldade de Aprendizagem. Revista Distúrbios Comum, São Paulo, 2, 241-252, 2013.

HEIN, Julia Margarida. et al. Avaliação Da Eficácia Do Software "Alfabetização Fônica" Para Alunos Com Deficiência Mental. Revista Brasileira de Educação Especial. Bauru, 1, p. 65-82, 2010. Disponível em: http://www.scielo.br/pdf/rbee/v16n1/06.pdf. Acesso em: 18 abr. 2020.

INSTITUTO BRASILEIRO DE GEOGRAFIA E ESTATÍSTICA. Pessoa com deficiência. Rio de Janeiro, RJ, 2010.

KENSKI, Vani Moreira. Educação e Tecnologias: o novo ritmo da informação. 8ª ed. Campinas: Papirus, 2012.

LIMA, Solange de Freitas Brando. Treino de Consciência Fonológica e Intervenção Comportamental em Ambientes familiar e escolar de crianças com Síndrome de Williams. 2015. Tese (Doutorado em distúrbios do desenvolvimento)- Universidade Presbiteriana Mackenzie, São Paulo, 2015. Disponível em:

http://tede.mackenzie.br/jspui/handle/tede/3083. Acesso em: 18 abr. 2020.

MEI, Chi Kow. Intervenção Coletiva no Uso do Programa de Alfabetização Fônica Computadorizada em Crianças da Recuperação do Ciclo I. 2007. Dissertação (Mestrado em Distúrbios do Desenvolvimento)-U̧niversidade Presbiteriana Mackenzie, São Paulo, 2007. Disponível em: http://tede.mackenzie.br/jspui/handle/tede/1678. Acesso em: 18 abr. 2020.

MURPHY, Cristina Ferraz Borges. Desenvolvimento de software para treinamento auditivo e aplicação em crianças com dislexia. 2008. Tese (Doutorado em Ciências)Universidade de São Paulo, São Paulo, 2018. Disponível em: https://www.teses.usp.br/teses/disponiveis/5/5162/tde-09062009203551/publico/TESE_CRISTINA_FERRAZ_BORGES_MURPHY.pdf. Acesso em: 18 abr. 2020.

NOVAIS, Carolina Bernardi de; MISHIMA, Fabíola; SANTOS, Patrícia Leila. Treinamento breve de consciência fonológica: impacto sobre a alfabetização. Revista de Psicopedagogia. São Paulo, 93, p. 189-200, 2013. Disponível em: http://www.revistapsicopedagogia.com.br/detalhes/95/treinamento-breve-de-conscienciafonologica--impacto-sobre-a-alfabetizacao. Acesso em: 18 abr. 2020. 
OLIVEIRA, Amália Rebouças de Paiva; MUNSTER, Mey de Abreu Van; GONÇALVES, Adriana. Garcia. Desenho Universal para Aprendizagem e Educação Inclusiva: uma Revisão Sistemática da Literatura Internacional. Revista Brasileira de Educação Especial, São Paulo, 4, p. 675-690, 2019. Disponível em: http://www.scielo.br/scielo.php?pid=S1413-65382019000400675\&script=sci_arttext\&tlng=pt. Acesso em: 18 abr. 2020.

PAIXÃO, Glenda Miranda da. Procedimento de Ensino e Teste de Leitura Recombinativa para Crianças com Paralisia Cerebral. 2012. Dissertação (Mestrado em Teoria e Pesquisa do Comportamento), Universidade Federal do Pará. Pará, 2012. Disponível em: http://ppgtpc.propesp.ufpa.br/ARQUIVOS/dissertacoes/glenda\%20miranda\%202012.pdf. Acesso em: 18 abr. 2020.

PAIXÃO, Glenda Miranda da; ASSIS, Grauben Jose Alves; OLIVEIRA, Ana Irene Alves. Emergência de leitura recombinativa em crianças com paralisia cerebral. Revista Brasileira de Terapia Comportamental e Cognitiva. São Paulo, 3, p. 4-22, 2014. Disponível em: http://www.usp.br/rbtcc/index.php/RBTCC/article/view/709. Acesso em: 18 abr. 2020.

PELOSI, Mirian Bonadiu. et al. Atividades Lúdicas Para o Desenvolvimento da Linguagem Oral e Escrita para Crianças e Adolescentes com Síndrome de Down. Revista Brasileira de Educação Especial, São Paulo, 4, p. 535-550, 2018. Disponível em:http://www.scielo.br/scielo.php?script=sci_abstract\&pid=S141365382018000400535\&lng=pt\&nrm=iso. Acesso em: 18 abr. 2020.

PESTUN, Magda Solange Vanzo. et al. Estimulação da consciência fonológica na educação infantil: prevenção de dificuldades na escrita. Revista Semestral da Associação Brasileira de Psicologia Escolar e Educacional, São Paulo, 1, p. 95-104, 2010. Disponível em: http://www.scielo.br/pdf/pee/v14n1/v14n1a11. Acesso em: 18 abr. 2020.

REIS, Marcia Regina. Constituição da Linguagem Escrita de uma Criança Considerada com Deficiência Intelectual: Contribuições da Perspectiva Histórico-Cultural. 2018. Tese (Doutorado em Educação)-Faculdade de Filosofia e Ciência, Universidade Estadual Paulista, São Paulo, 2018. Disponível em: https://www.marilia.unesp.br/Home/PosGraduacao/Educacao/Dissertacoes/reis_mr_do_mar.pdf. Acesso em: 18 abr. 2020.

RODRIGUES, Pauliana do Nascimento. Efeitos da exposição combinada a programas informatizados de ensino de leitura, escrita e consciência fonológica a alunos com dificuldade de aprendizagem. 2017. Dissertação (Mestrado em Educação Especial)Centro de Educação e Ciências Humanas, Universidade Federal de São Carlos, São Paulo, 2017. Disponível em:

https://repositorio.ufscar.br/bitstream/handle/ufscar/9060/DissPNR.pdf?sequence=1\&isAllow ed=y. Acesso em 18 abr. 2020.

SAS, Roberta Moreno. Efeitos de um Programa de Remediação Fonológica nas Habilidades de Leitura e Escrita em Alunos com Síndrome de Down. Dissertação (Mestrado em Educação Especial)-Centro de Educação e Ciências Humanas, Universidade Federal de São Carlos, São Paulo, 2009. Disponível em: https://repositorio.ufscar.br/bitstream/handle/ufscar/3004/2278.pdf?sequence=1. Acesso em: 18 abr. 2020. 
http://dx.doi.org/10.5902/1984686X43678

SEABRA, Alessandra Gotuzo; CAPOVILLA, Fernando Cesar. Alfabetização: Método Fônico. 5ª̂ed. São Paulo: Memnon, 2010.

SERGIN, Miriam. Alfabetização e Deficiência Intelectual: Estudo Sobre o Desenvolvimento de Habilidade Fonológicas em Crianças com Síndrome de Williams e Síndrome de Down. Tese (Doutorado em Distúrbios do Desenvolvimento)-Universidade Presbiteriana Mackenzie, São Paulo, 2015. Disponível em:

http://tede.mackenzie.br/jspui/handle/tede/1783. Acesso em: 18 abr. 2020.

SILVA, Ângela Carrancho. Educação e Tecnologia: Entre o Discurso e a Prática. Ensaio: Avaliação Politica Pública Educacional, Rio de janeiro, 72, p.527-554, 2011. Disponível em: http://www.scielo.br/pdf/ensaio/v19n72/a05v19n72.pdf. Acesso em: 18 abr. 2020.

SILVA, Claudia da. Eficácia de um Programa de Remediação Fonológica e Leitura em Escolares com Distúrbio de Aprendizagem. 2009. Dissertação (Mestrado em Educação)-Universidade Estadual Paulista, Marília, 2009. Disponível em: https://www.marilia.unesp.br/Home/PosGraduacao/Educacao/Dissertacoes/silva_c_me_mar.pdf. Acesso em: 18 abr. 2020.

SOUZA, Noeni Tamar Américo de. Todos podem aprender: uma intervenção com crianças do $3^{\circ}$ ano do Ensino Fundamental com atrasos na aprendizagem da linguagem escrita. 2018. Dissertação (Mestrado em Educação: Psicologia da Educação)-Pontifícia Universidade Católica de São Paulo, São Paulo, 2018. Disponível em: https://tede2.pucsp.br/handle/handle/21445. Acesso em: 18 abr. 2020.

\section{YOSHIDA, Maria Carolina Cabeste Gamba (2017). Atividades de Estimulação da} Consciência Fonológica por meio de um Livreto Destinado a Alunos com Deficiência Auditiva/Surdez. 2017. Dissertação (Mestrado em Psicologia do Desenvolvimento e Aprendizagem)-Universidade Estadual Paulista Júlio De Mesquita Filho, Bauru, 2017. Disponível em: https://repositorio.unesp.br/bitstream/handle/11449/150734/yoshida_mccg_me_bauru.pdf? sequence=3. Acesso em 18 abr. 2020.

\section{Nota}

${ }^{1}$ Entenda-se dificuldade de aprendizagem, quando os estudos não especificam informações diagnósticas, referindo-se apenas a baixo repertório de leitura, escrita e/ou CF ou repetência escolar. A literatura aponta que indivíduos com dificuldade de aprendizagem não apresenta causas orgânicas que justifique o fracasso escolar, estas ligada a fatores emocionais, sociais, familiares, a problemas de ordem e origem pedagógica e a não capacitação em pré-requisitos para alfabetização (CARVALHO; CRENITTI; CIASCA, 2007). 